\title{
Design and simulation of the space vector modulation and applied to a load RL powered by a voltage inverter
}

\author{
Marouane El Azzaoui* and Hassane Mahmoudi \\ Electronics Power and Control Team, Department of Electrical Engineering, Mohammadia School of Engineers, \\ Mohamed V University Agdal, Rabat, Morocco
}

Received: 19-June-2016; Revised: 18-July-2016; Accepted: 22-July-2016

(C)2016 ACCENTS

\begin{abstract}
The vector control performance applied to rotating machines depends largely on static and dynamic characteristics of the inverter associated with it. The development of the pulse-width modulation (PWM) provided greater flexibility in the control of the converters. The objective of this work is to construct a simplified and practical space vector modulation (SVM) based on the selection of the sequence and the calculation of the conduction time or extinction. We have presented the blocks of the simulation vector modulation on the Matlab / Simulink with a new method for determining conduction time and analyzed its application on a load RL supplied by a voltage inverter. The performance of the proposed method has been presented by the simulation results.
\end{abstract}

Keywords

SVM, PWM, Vector control, Inverter.

\section{Introduction}

The often adapted to static converter is the PWM control strategy [1-3]. Several methods have been developed with the objective of generating the output of the inverter a sinusoidal voltage with the least possible harmonic [4]. There are several PWM methods in literature such as the sinusoidal PWM (SPWM) [5, 6] or elimination of third harmonic PWM (THPWM) [7] and SVM [8].

The goal of this work is to achieve a simplified and practical SVM, which can be easily implemented in a digital processor. The principle of this method is the determination of time portions (modulation period) to be allocated to each voltage vector during the sampling period [9]. This close control is used to determine the sequences of firings and extinctions of converter components and minimize harmonic. A simulation of the overall system using MATLAB / Simulink allows highlighting the performance of SVM.

\section{Principle of SVM}

In this modulation, a single vector represents the three sinusoidal voltage outputs that are desired.

*Author for correspondence

153
At best, this vector is approximated for each modulation interval by acting on the control of the three sets of complementary switch. This PWM is not based on separate calculations for each arm of the inverter, but on the determination of a global control vector approximated on a modulation period $\mathrm{T}$ [9].

\section{Steps in the realization of blocks SVM}

There are six steps to realizing SVM:

Step 1: determination of reference voltages $\mathrm{V} \alpha, \mathrm{V} \beta$.

Step 2: identification of sectors.

Step 3: calculation of the variables $\mathrm{X}, \mathrm{Y}$ and $\mathrm{Z}$.

Step 4: calculation of $\mathrm{t} 1$ and $\mathrm{t} 2$ for each sector.

Step 5: generation of the modulating signals taon, tbon and tcon.

Step 6: pulse generation series $\mathrm{Ta}, \mathrm{Tb}$ and Tc.

\section{Presentation of blocks of SVM in Simulink}

The SVM simulation system is based on MATLAB / Simulink that is selected as an environment essential due to its various advantages: high efficiency programming, stylish graphical interface, open architecture allowing adaptation to the needs.

\subsection{Simulink block of SVM}

The simulation of this technique is done through the model in Figure 1. 


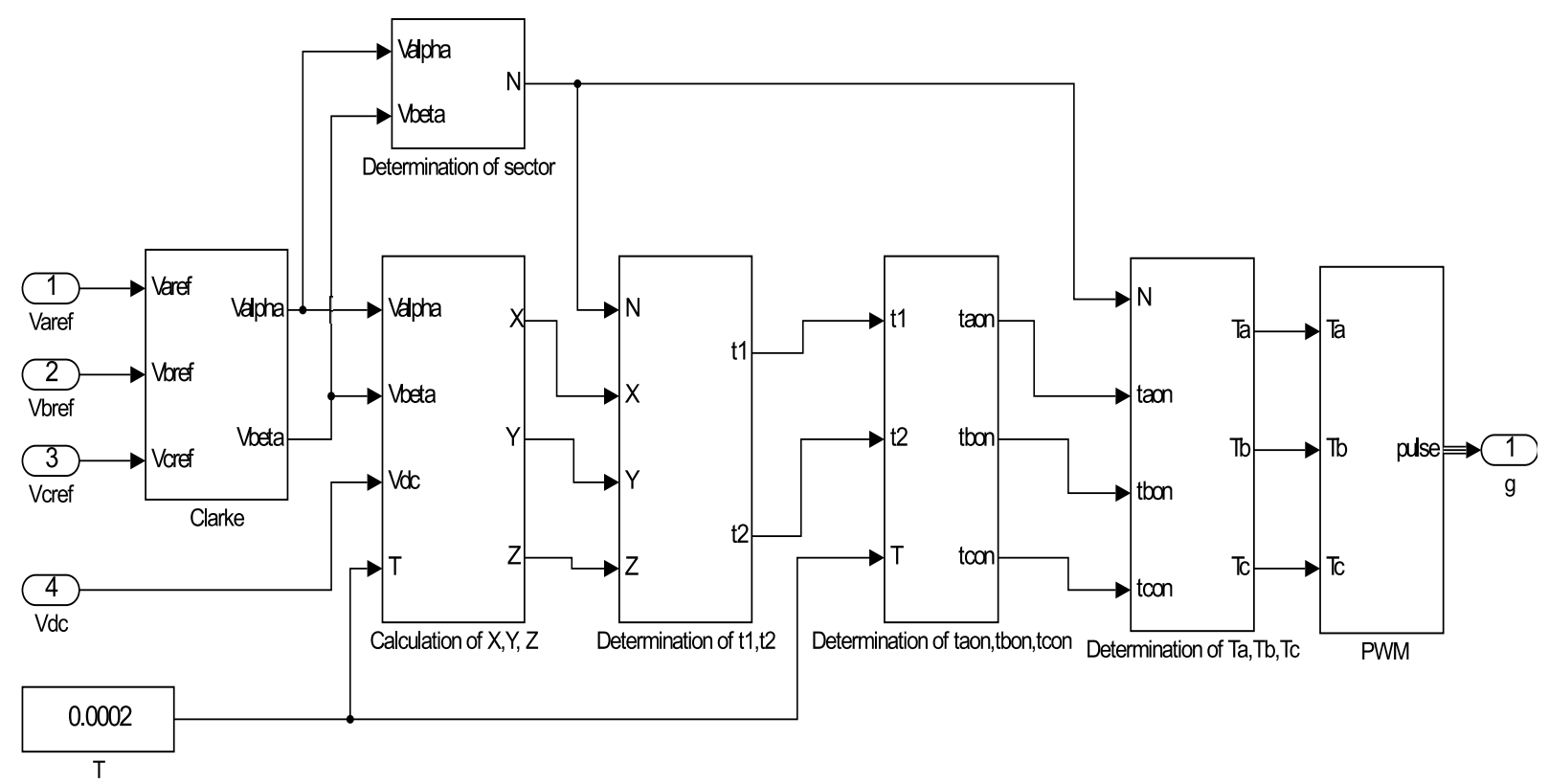

Figure 1 Block diagram of SVM

\subsection{Determining $V_{\alpha}, V_{\beta}$}

The block of Figure 2 is used to project the threephase voltages in the repository $(\alpha, \beta)$ by performing the transformation of Clarke in Simulink. U (1) is the input for Varef, u (2) is the input for Vbref, u (3) is the input for Vcref. These blocks are the s-function of
Simulink. The topologies are used to call Varef, Vbref, and Vcref. Fen and Fen1 are the name of the blocks. Varef, Vbref, and Vcref, are the reference sinusoidal voltages. $\mathrm{N}$ is the sector.

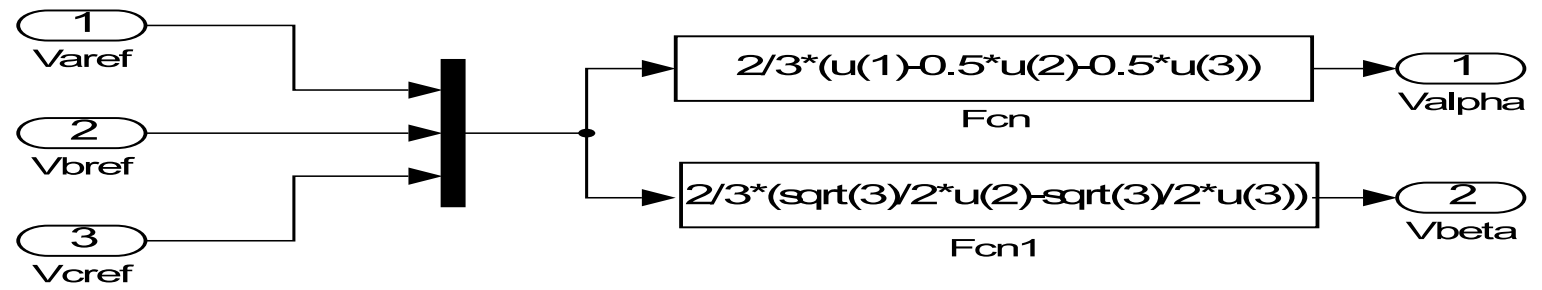

Figure 2 Block transformation of Clarke

\subsection{Identifying sectors}

The sector determination algorithm is illustrated in Figure 3.

\subsection{Calculation of variables $X, Y$ and $Z$}

The three variables are given by the following equations:

$X=\sqrt{3} \cdot \frac{T}{V d c} \cdot V_{\beta}$

$Y=\frac{\sqrt{3}}{2} \cdot \frac{T}{V d c} \cdot V_{\beta}+\frac{3}{2} \cdot \frac{T}{V d c} \cdot V_{\alpha}$

$Z=\frac{\sqrt{3}}{2} \cdot \frac{T}{V d c} \cdot V_{\beta}-\frac{3}{2} \cdot \frac{T}{V d c} \cdot V_{\alpha}$
$\mathrm{T}$ is the sampling time and $\mathrm{Vdc}$ is the DC voltage on one side of the inverter. The Simulink block is presented in Figure 4.

\subsection{Calculation of $\mathbf{t} 1$ and $\mathbf{t} 2$}

In this step, the block determines the times $\mathrm{t} 1$ and $\mathrm{t} 2$ for each sector from the values of $\mathrm{X}, \mathrm{Y}$ and $\mathrm{Z}$ according to the Table 1. The Simulink block is presented in Figure 5.

Table 1 Calculation of $\mathrm{t} 1$ and $\mathrm{t} 2$

\begin{tabular}{lllllll}
\hline Sector & $\mathbf{1}$ & $\mathbf{2}$ & $\mathbf{3}$ & $\mathbf{4}$ & $\mathbf{5}$ & $\mathbf{6}$ \\
\hline $\mathrm{t} 1$ & $-\mathrm{Z}$ & $\mathrm{Z}$ & $\mathrm{X}$ & $-\mathrm{X}$ & $-\mathrm{Y}$ & $\mathrm{Y}$ \\
$\mathrm{t} 2$ & $\mathrm{X}$ & $\mathrm{Y}$ & $-\mathrm{Y}$ & $\mathrm{Z}$ & $-\mathrm{Z}$ & $-\mathrm{X}$ \\
\hline
\end{tabular}




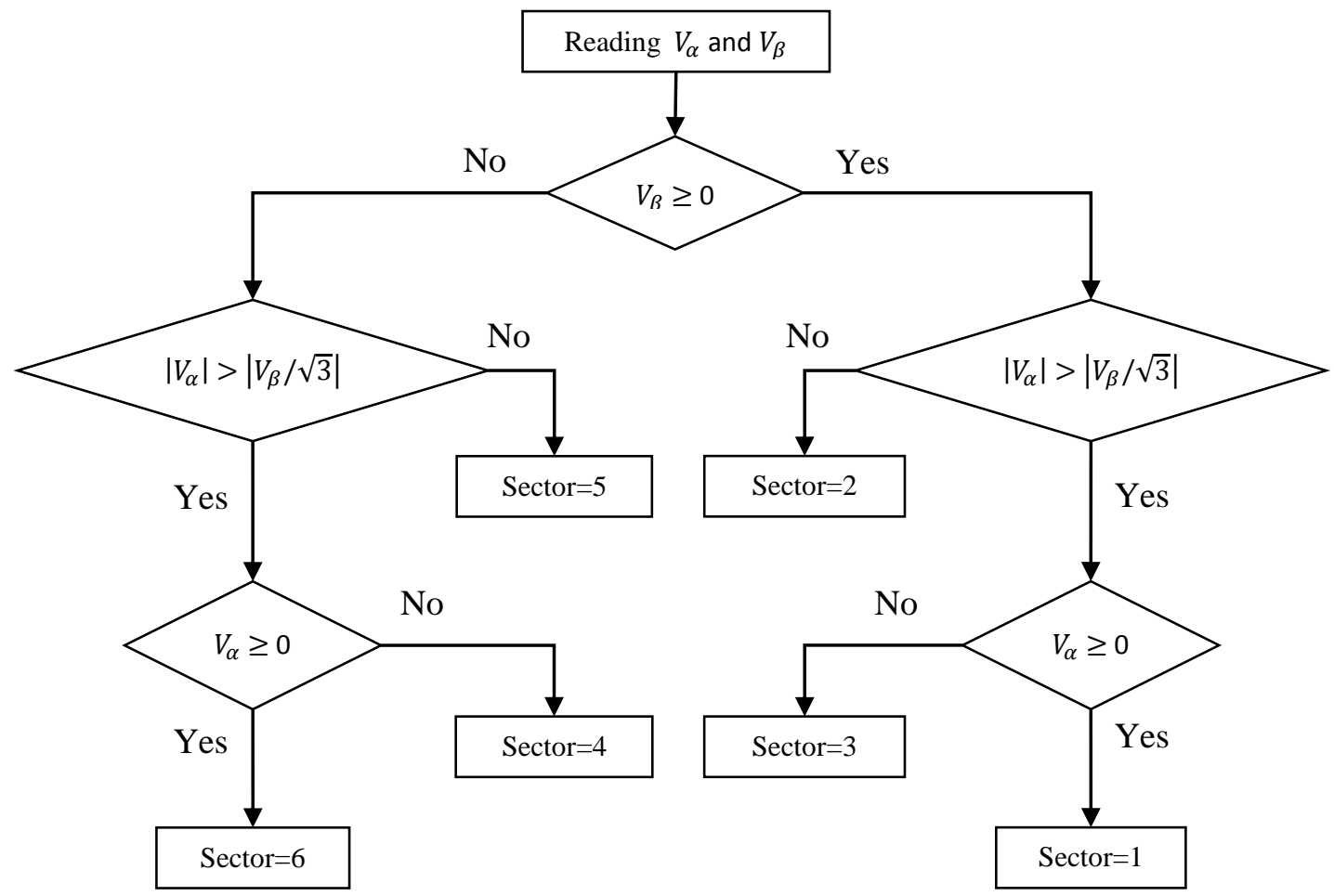

Figure 3 Algorithm for determining the sector

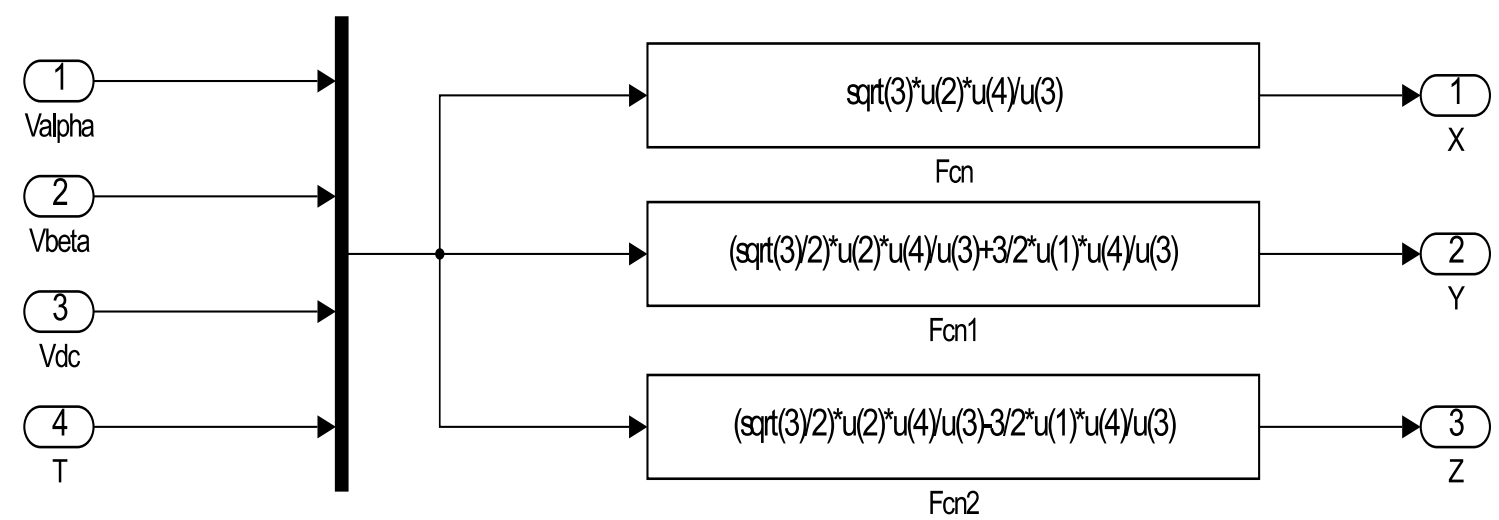

Figure 4 Calculation block of $\mathrm{X}, \mathrm{Y}$ and $\mathrm{Z}$

4.6Determination of taon, tbon and tcon taon $=(\mathrm{T}-\mathrm{t} 1-\mathrm{t} 2) / 2$

tbon $=$ taon $+\mathrm{t} 1$

$\mathrm{tcon}=\mathrm{tbon}+\mathrm{t} 2$

We adopt the Simulink model in Figure 6.

4.7Determination of $\mathrm{Ta}, \mathrm{Tb}$ and $\mathrm{Tc}$

The txon signals are ordered in a certain way (Table 2).
Table 2 Calculation of $\mathrm{Ta}, \mathrm{Tb}$ and $\mathrm{Tc}$

\begin{tabular}{lllllll}
\hline $\begin{array}{l}\text { Sector } \\
\text { phase }\end{array}$ & $\mathbf{1}$ & $\mathbf{2}$ & $\mathbf{3}$ & $\mathbf{4}$ & $\mathbf{5}$ & $\mathbf{6}$ \\
\hline $\mathrm{Ta}$ & taon & tbon & tcon & tcon & tbon & taon \\
$\mathrm{Tb}$ & tbon & taon & taon & tbon & tcon & tcon \\
$\mathrm{Tc}$ & tcon & tcon & tbon & taon & taon & tbon \\
\hline
\end{tabular}

Simulink model is presented in Figure 7. 
Marouane El Azzaoui et al.

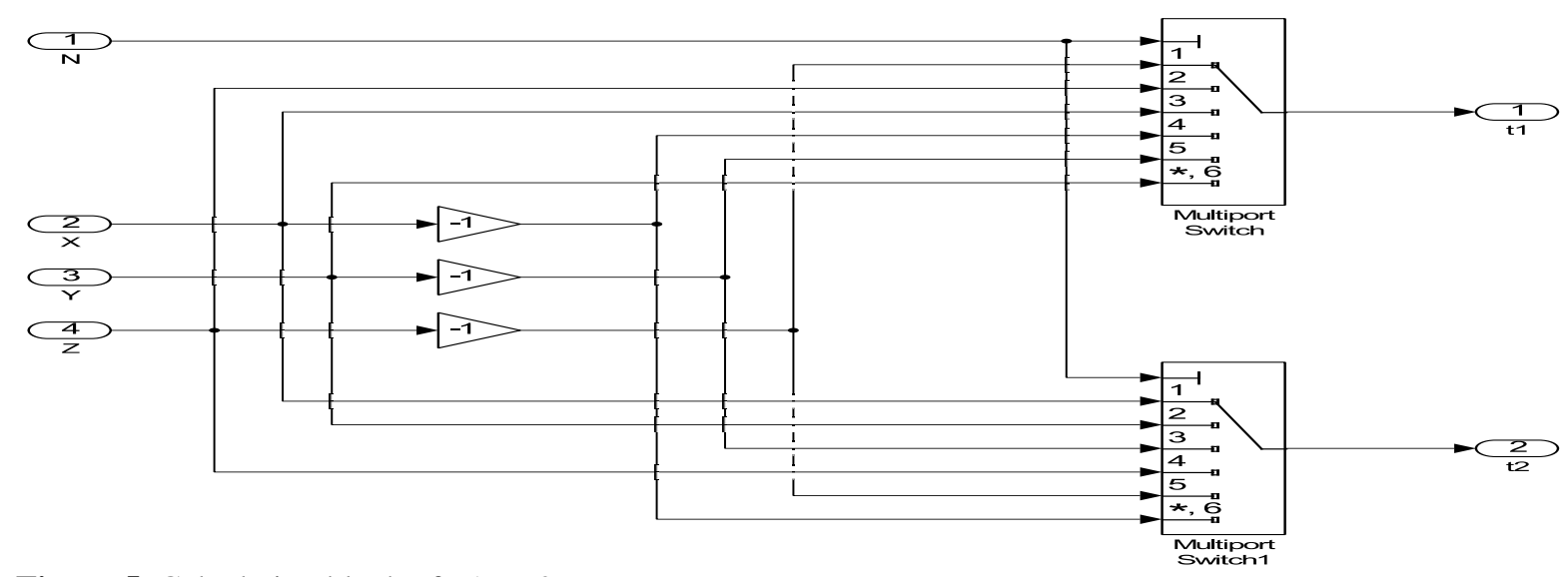

Figure 5 Calculation block of $\mathrm{t} 1$ et $\mathrm{t} 2$

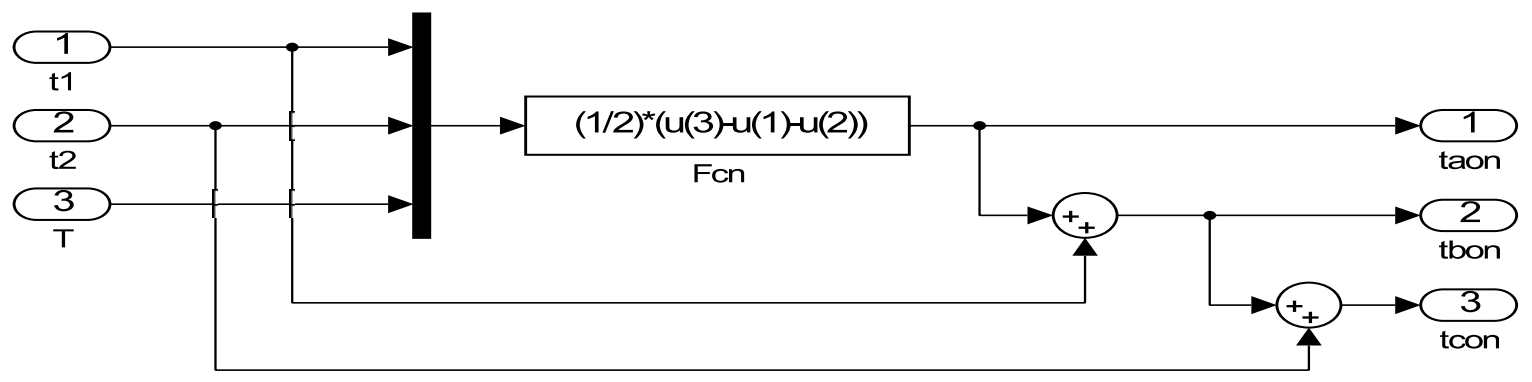

Figure 6 Determination block of taon, tbon et tcon

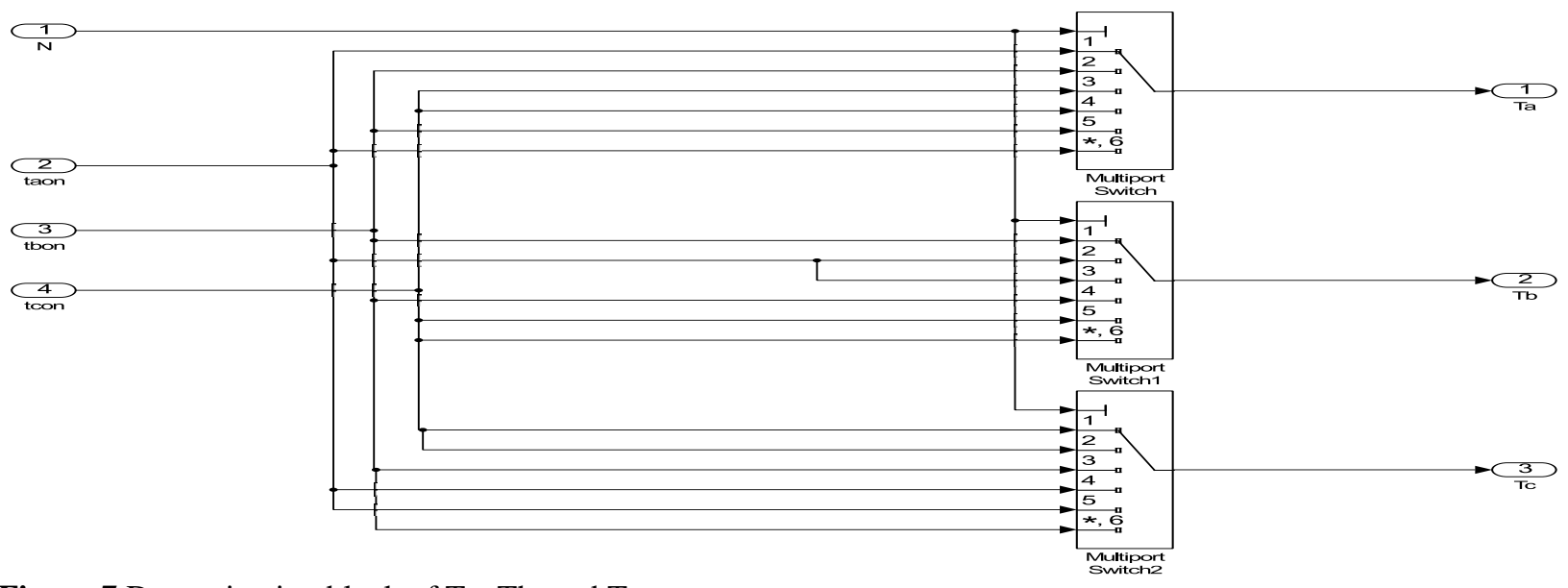

Figure 7 Determination block of $\mathrm{Ta}, \mathrm{Tb}$, and $\mathrm{Tc}$

\subsection{Generating PWM signals}

This block generates impulse series that will then be used to realize the control signals within the inverter model, following the comparison of modulating signals with high frequency triangular carrier (5 $\mathrm{kHz}$ ). Under Simulink, this block is shown in Figure $8[10]$.
The block test of SVM on a load RL driven by inverter is shown by the block in Figure 9. The results of the proposed technique are presented in Figures 10, 11, 12 and 13.

The currents are sinusoidal and voltages have rectangular shapes which represent two voltage thresholds $\frac{2 V_{d c}}{3}$ and $\frac{V_{d c}}{3}$. Figure 12 shows the change in the sector and Figure 13 shows a phase of the PWM control signals. 


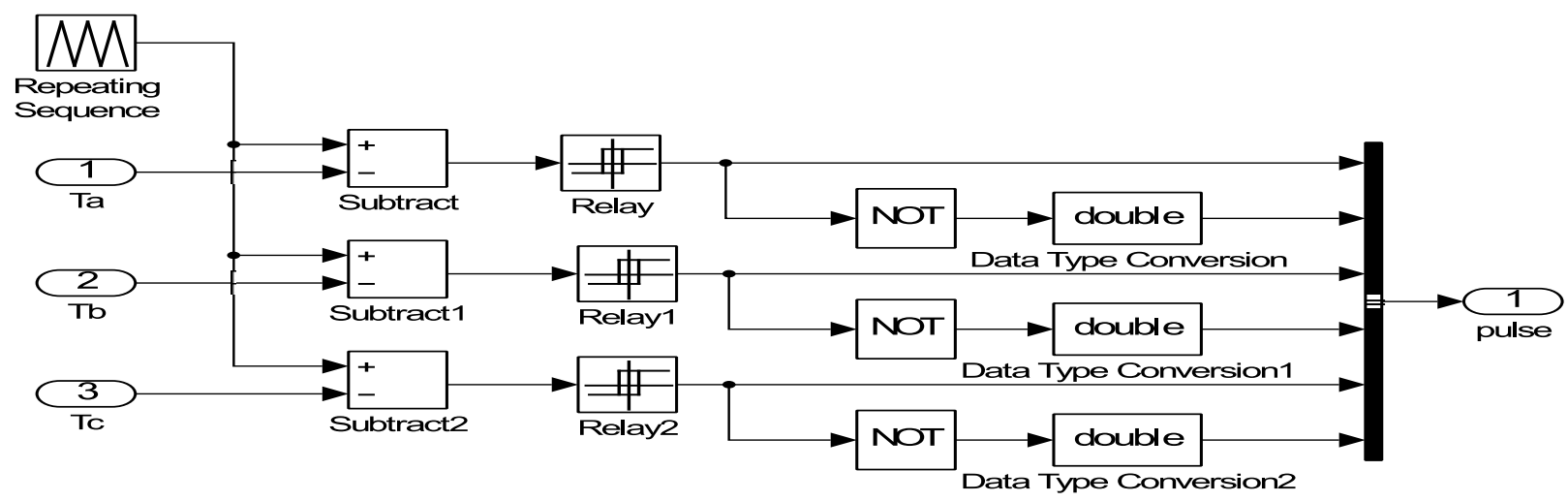

Figure 8 Pulses generation blocks

\section{Simulation results}

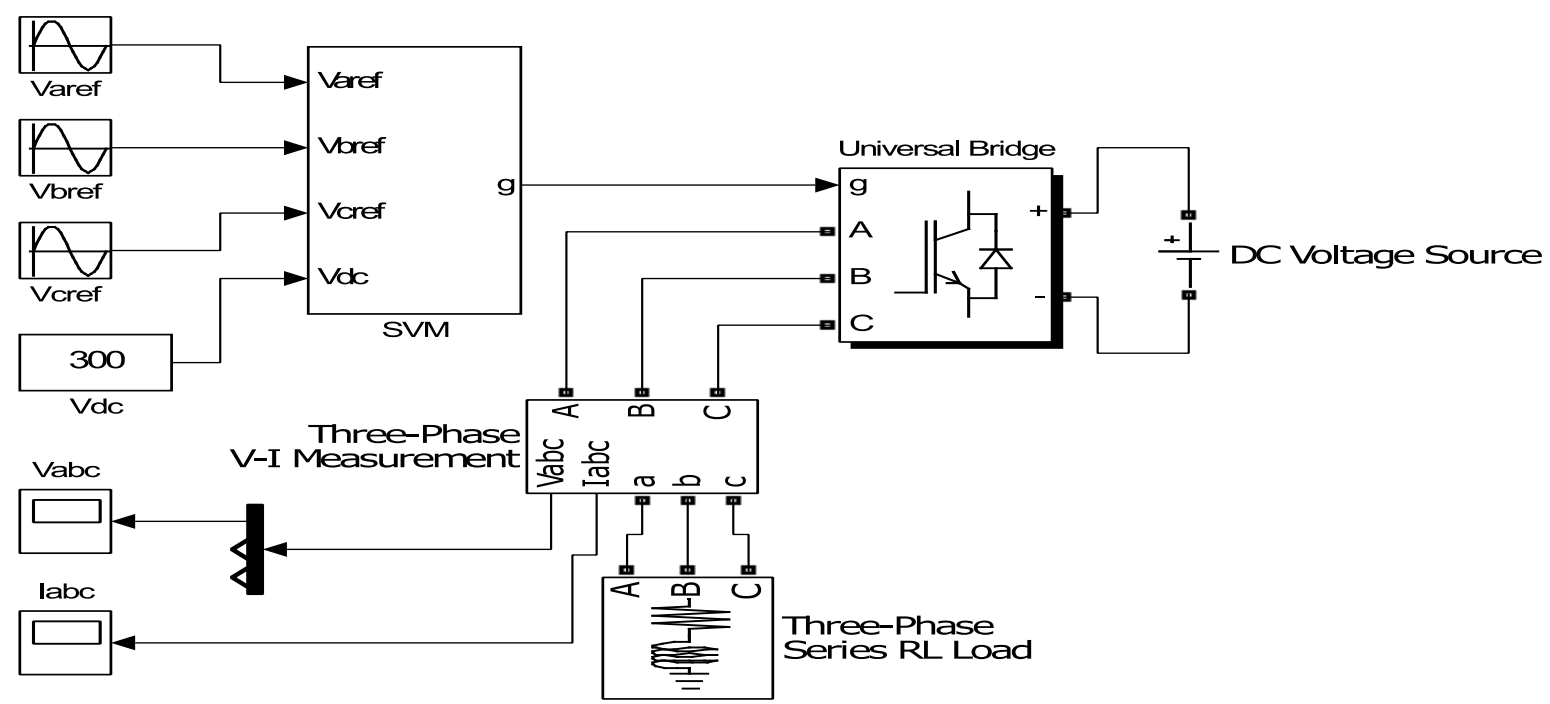

Figure 9 Full system block diagram

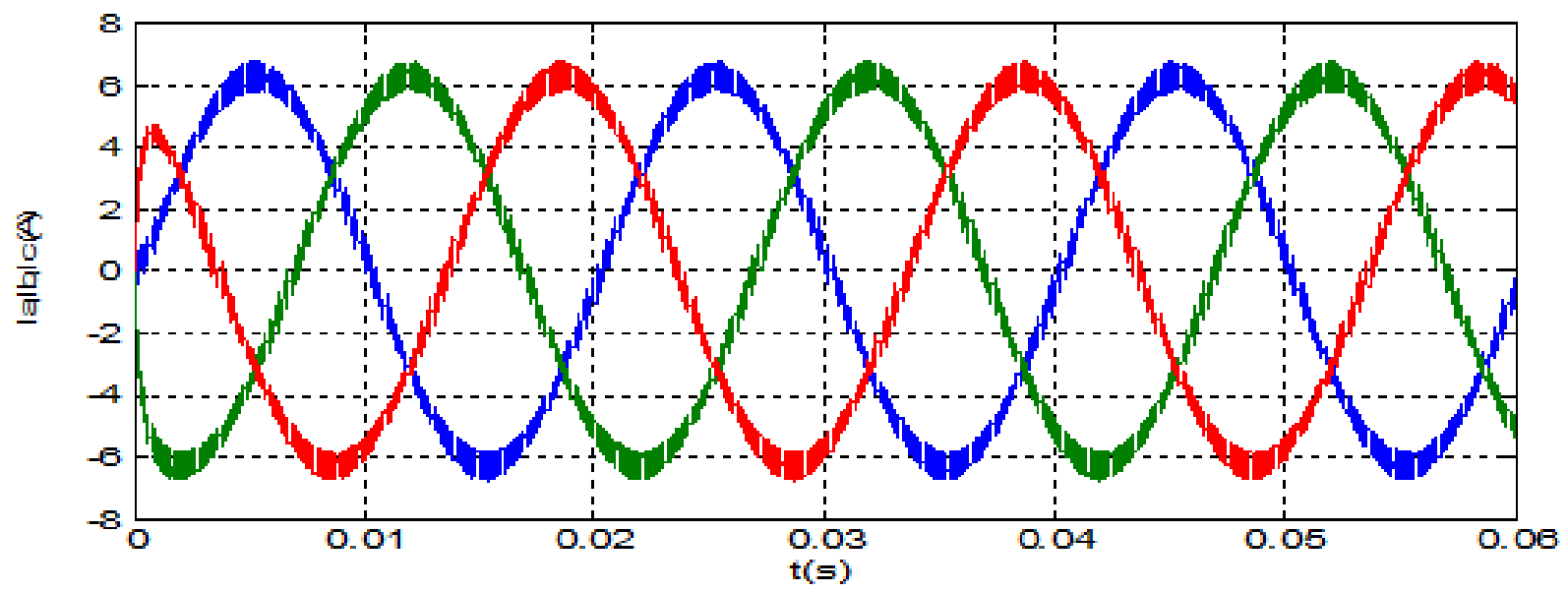

Figure 10 The phase currents 
Marouane El Azzaoui et al.

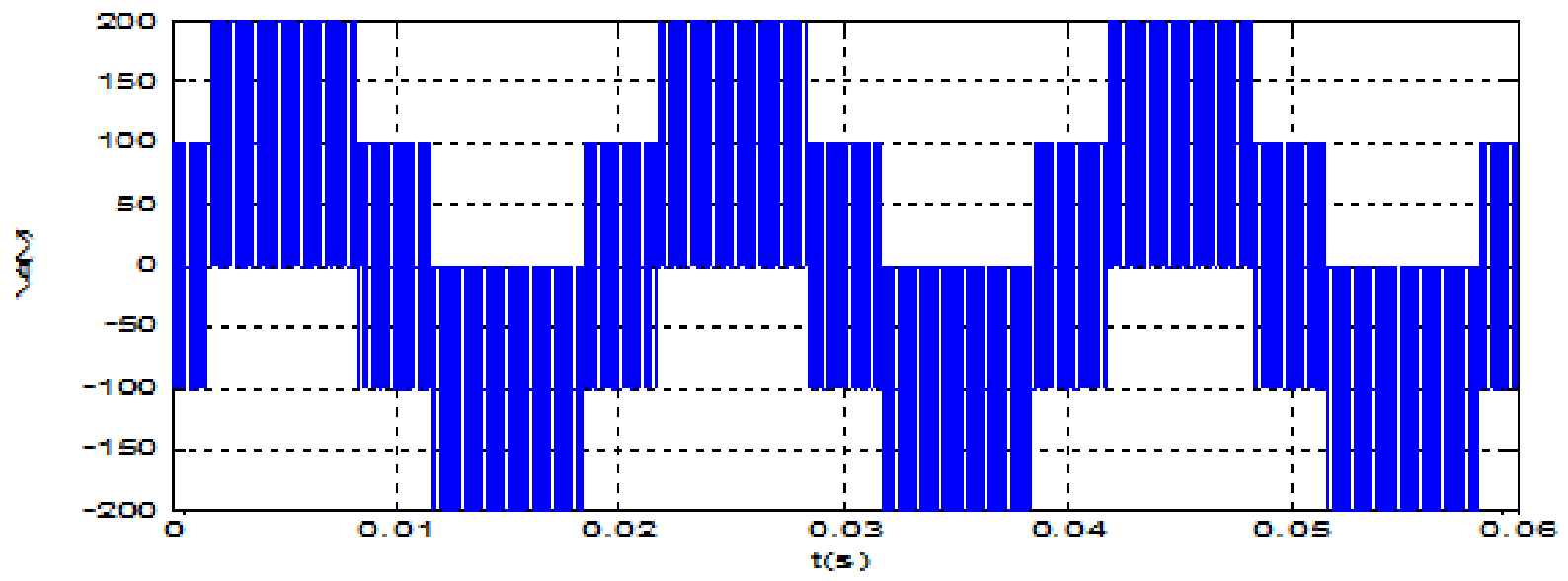

Figure 11 The phase voltages

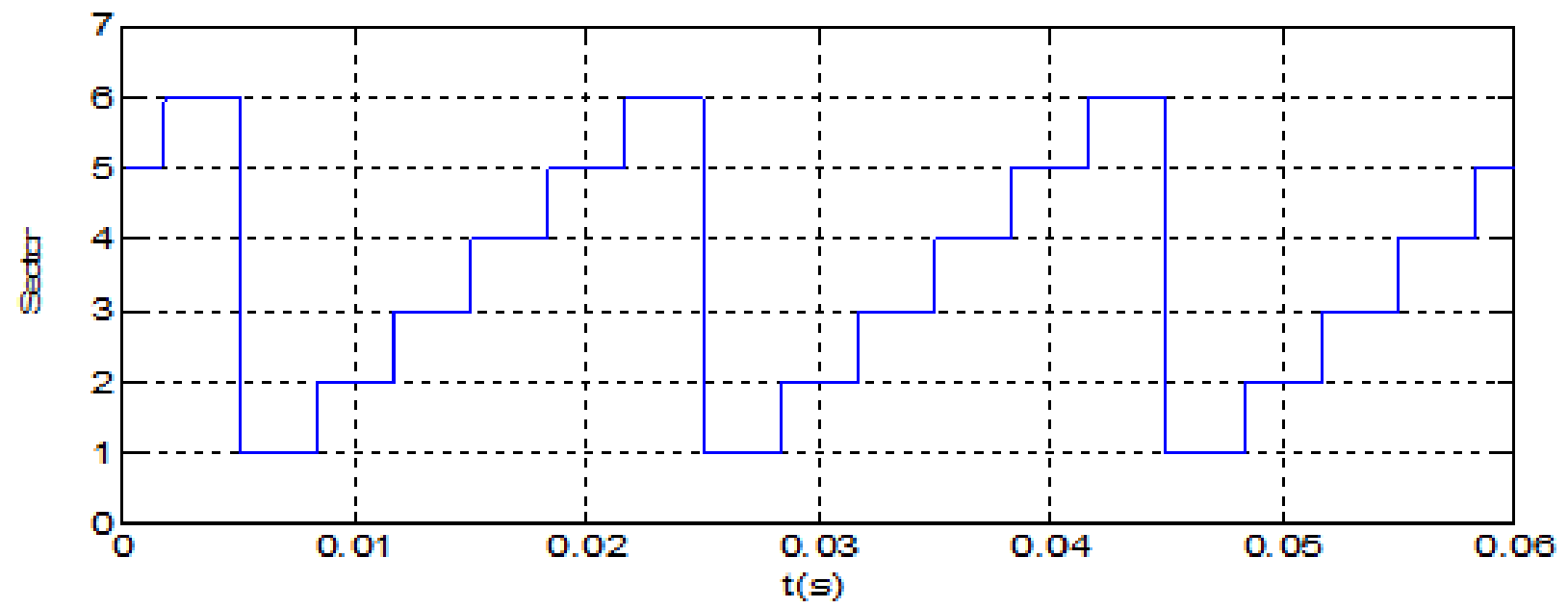

Figure 12 Variation of sector

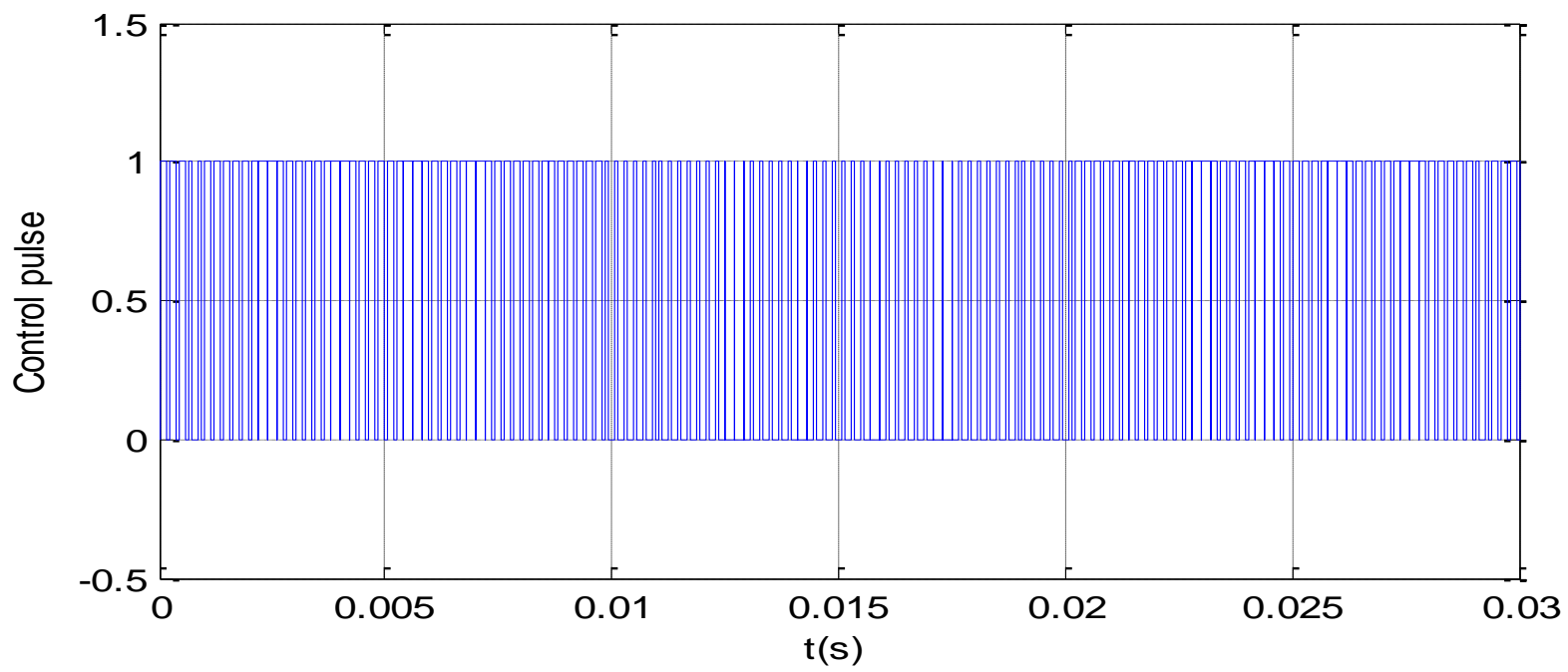

Figure 13 Control pulse 


\section{Discussion}

The results show that the currents are three phases, but are not purely sinusoidal because of the harmonics generated by the inverter. Comparing the currents obtained using SPWM $[6,7]$ and the simplified SVM depicted in this paper, it's clear that SVM reduces more the harmonics to get sinusoidal currents. The voltage at the output of the inverter is represented by two values $\frac{2 V_{d c}}{3}$ and $\frac{V_{d c}}{3}$ because the inverter used is based on two levels. Figure 12 shows the reference voltage moving from the sector 1 to sector 6 which means that this voltage rotates a frequency imposed by the three phase references. Finally, the pulses generated by the using of the SVM method are presented in Figure 13.

\section{Conclusion}

In this paper, we studied SVM, and have established its model with Matlab / Simulink. The SVM technique is generally complicated in theory and difficult in practice, but executing the simulation based on Matlab / Simulink and with the use of the new technique of computing time, may represent the behavior of SVM more easily and clearly. Simulation results are presented to demonstrate the validity of the SVM technique. For a future vision of this work, an experimental approach will be implemented to validate this technique.

\section{Acknowledgment}

None.

\section{Conflicts of interest}

The authors have no conflicts of interest to declare.

\section{References}

[1] Mitran IA, Linca M. Energetical performances of sinusoidal PWM control of voltage inverter and induction motor drive system. In proceedings of the 3rd international youth conference on energetics (IYCE) 2011 (pp. 1-6). IEEE.

[2] $\mathrm{Lu} \mathrm{X}$, Chen $\mathrm{S}, \mathrm{Wu} \mathrm{C}, \mathrm{Li} \mathrm{M}$. The pulse width modulation and its use in induction motor speed control. In fourth international symposium on computational intelligence and design (ISCID) 2011 (pp. 195-8). IEEE.

[3] Das A, Nademi H, Norum L. A pulse width modulation technique for reducing switching frequency for modular multilevel converter. In India international conference on power electronics (IICPE) 2011 (pp. 1-6). IEEE.

[4] Alexa IA, Onea A. Fast calculating PWM techniques of voltage source inverter. In 18th international conference on system theory, control and computing (ICSTCC) 2014 (pp. 526-31). IEEE.
[5] Vadhiraj S, Swamy KN, Divakar BP. Generic SPWM technique for multilevel inverter. In Asia-pacific power and energy engineering conference (APPEEC) 2013 (pp. 1-5). IEEE.

[6] Shu-lin L, De-fang L. Research on SPWM inverter controller based on FPGA. In international conference on electrical and control engineering (ICECE) 2011 (pp. 4915-8). IEEE.

[7] Sahoo SK, Ramulu A, Batta S, Duggal S. Performance analysis and simulation of three phase voltage source inverter using basic PWM techniques. In IET Chennai 3rd international on sustainable energy and intelligent systems (SEISCON 2012) 2012 (pp. 1-7). IET.

[8] Sanusi S, Ibrahim Z, Jidin A, Jopri MH, Karim KA, Othman MN. Implementation of space vector modulation for voltage source inverter. In international conference on electrical machines and systems (ICEMS) 2013 (pp. 1361-6). IEEE.

[9] Quang NP, Dittrich JA. Vector control of three-phase AC machines. Berlin, Heidelberg: Springer; 2008.

[10] Zhou K, Wang D. Relationship between space-vector modulation and three-phase carrier-based PWM: a comprehensive analysis [three-phase inverters]. IEEE Transactions on Industrial Electronics. 2002; 49(1):186-96.

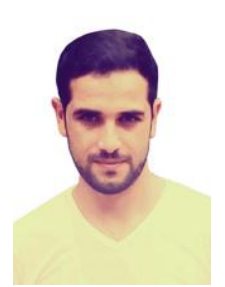

Marouane El Azzaoui was born in Morocco on May 14, 1986, he received his bachelor degree with honors in 2005, then he obtained a university degree at the University of Technology of Moulay Ismail in Meknes in 2008 and he won the state engineer diploma in electrical engineering, his research focuses on the control laws to optimize the production of wind energy, currently he continues his doctoral study in Mohammadia Engineering School, Mohammed V University, Rabat, Morocco.

Email: marouan.elazzaoui@gmail.com

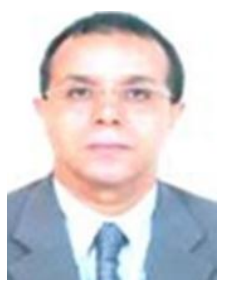

Hassane Mahmoudi was born in Meknes, Morocco, on January 4, 1959. He received B.S degree in electrical engineering from Mohammadia School of Engineers, Rabat, Morocco, in 1982, and the Ph.D degree in power electronic from Montefiore Institute of Electrical Engineering, Luik, Belgium, in 1990. He was an assistant professor of physics, at the Faculty of Sciences, Meknes, Morocco, from 1982 to 1990. Since 1992, he has been a professor at the Mohammadia Schools of Engineers, Rabat, Morocco, and he was the head of electric engineering department during four years (1999, 2000, 2006 and 2007). His research interests include static converters, electrical motor drives, active power filters and the compatibility electromagnetic. 